\title{
Synthesis of Sildenafil Citrate Validated HPLC Method and Its Pharmaceutical Dosage Forms
}

\author{
Krishna Sarma Pathy* and Sriraman Chakaravathy \\ Department of Chemistry, IPL research center Lucknow, sriramanchakravarthy, Consultant API, vadodara, india
}

Submission: March 16, 2018; Published: March 22, 2018

"Corresponding author: Krishna Sarma Pathy, Department of Chemistry, IPL research center Lucknow, sriramanchakravarthy, Consultant API, vadodara, india, India; Email: drkrishnasarmapathy@yahoo.in

Abstract

The present study describes analytical method of 1-[[3-(6,7-dihydro-1-methyl-7-oxo-3-propyl-1H-pyrazolo[4,3-d]pyrimidin-5-yl)-4ethoxyphenyl]sulphonyl]-4methypiperazine citrate (sildenafil Citrate). The following specification particularly describes and ascertains the nature of this invention, and the manner in which it is to be performed. Sildenafil is an oral drug used primarily to treat male sexual function problems (impotence or erectile dysfunction) since becoming available in 1998. It is a potent and selective inhibitor of cGMP specific Phosphodiesterase Type 5 (PDE5) in the corpus cavernosum, where PDE5 is responsible for degradation of cGMP. Sildenafil has a peripheral site of action on erections. This substance has no direct relaxant effect on isolated human corpus cavernosum but potently enhances the relaxant effect of nitric oxide on this tissue. However, there is no analytical method for determination of this active compound in pharmaceutical preparations in the current European and US Pharmacopoeia. The aim of this study was to develop and validate HPLC method for sildenafil analysis in pharmaceutical dosage forms.

Keywords: Chlorosulphonyl Intermediate; N-Methylpiperazine; Sildenafil; IR; HPLC Validation

Abbreviations: PDE5: Phosphodiesterase Type 5; GMP: Guanosine Monophosphate; LOD: Limit of Detection; LOQ: Limit of Quantification; cGMP: Cyclicguanosine Monophosphate

\section{Introduction}

Sildenafil citrate is a selective inhibitor of cyclic Guanosine Monophosphate (GMP) or Specific phosphodiesterase type 5 (PDE 5), commercially developed by Pfizer, Inc._as Viagra ${ }^{\circledR}$. Sildenafil citrate is designated chemically as 1-[[3-(6,7-dihydro1-methyl-7-oxo-3-propyl-1H-pyrazolo[4,3-d]pyrimidin-5-yl)-4ethoxyphenyl]sulphonyl]-4-methypiperazine citrate (Figure 1) [1]. The compound has the following structure:<smiles>CCCc1nn(C)c2c(=O)[nH]c(-c3cc(S(=O)(=O)N4CCN(C)CC4)ccc3OCC)nc12</smiles><smiles>O=C(O)CC(O)(CC(=O)O)C(=O)O</smiles>

(5)

Figure 1.

The manufacture of Sildenafil citrate has been described in various patents and to cite a few references, EP 1002798, EP 1779852, EP 0916675, US6066735, US6204383, US2010048897, W00119827, W0122918, and W02004072079.
With respect to polymorphic forms of sildenafil citrate, while there are no patents reported, but in a publication describe three polymorphic forms. The process for the preparation of sildenafil citrate of polymorphic form I as designated (Figure 2).

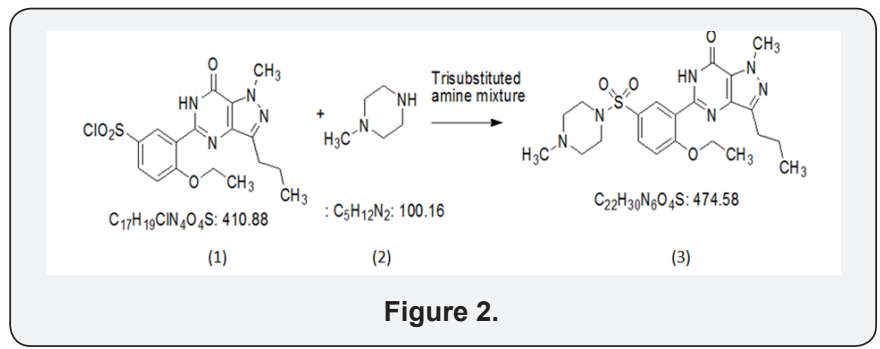

The process is from the penultimate intermediate namely 5-(5-chlorosulphonyl-2-ethoxy phenyl) -1-methyl-3-N-propyl1,6-dihydro-7H-pyrasolo-(4,3-d)pyrimidin-7-one, which is herein will be referred to as chlorosulphonyl intermediate (21). This intermediate is condensed with N-methylpiperazine (2) in a solvent preferably of chlorinated hydrocarbon in presence of a trisubstituted amine or in presence of mixture of such amines (Figure 3) [2]. 


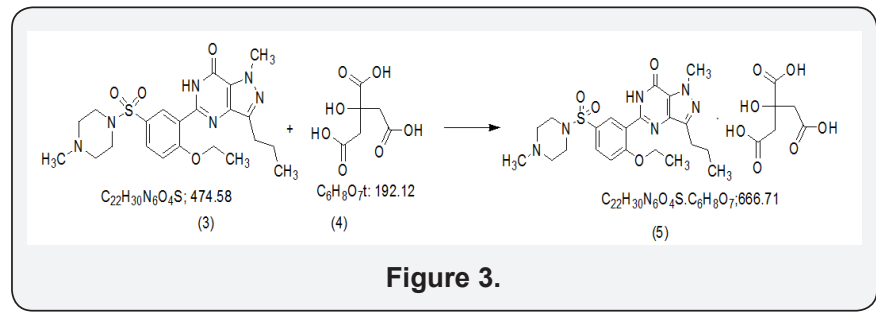

The resulting product of condensation namely sildenafil base is reacted with citric acid in an aqueous medium to give sildenafil citrate (3). The crystallization conditions are well established to give crystalline form I [3]. The powder X-ray diffraction pattern of the sildenafil citrate polymorphic form I as given in Figure 1 and the $2 \theta$ values are given in Table 1.

The Differential scanning calorimeter graph of the Sildenafil citrate polymorph I under specific conditions shows the melting point around $197.56{ }_{-}^{\circ} \mathrm{C}$. Figure 3 depicts a comparison of DSC scanned at $5{ }_{-}^{\circ} \mathrm{C} / \mathrm{min}$ over a temperature range of $30_{-}{ }^{\circ} \mathrm{C}$ to $350_{-}{ }^{\circ} \mathrm{C}$ for sildenafil citrate polymorphic form 1 [4].

\section{Materials and Methods}

HPLC analysis was performed using a Schimadzu LC-2010 chromatographic system (Schimadzu, Kyoto, Japan) consisting of a LC-20AT Prominence liquid chromatography pump with DGU20A5 Prominence degasser, a SPD-M20A Prominence Diode Array Detector, RF 10AXI fluorescence detector and a SIL-20 AC Prominence auto sampler. Data analyses were done using Class VP 7.3 Software [5,6]. The elution was carried out on a column Hypersil BDS-C18 (125 x 4 mm i.d., 5 mm), mobile phase consisted of phosphate buffer $(20 \mathrm{mM}, \mathrm{pH} 2.8)$-acetonitrile $(71: 29, \mathrm{~V} / \mathrm{V})$, flow rate $1.5 \mathrm{~mL} \mathrm{~min}-1$, at controlled temperature $\left(25{ }^{\circ} \mathrm{C}\right)$ and auto sampler temperature at $4{ }_{-}^{\circ} \mathrm{C}$. Detection of sildenafil was carried out at $285 \mathrm{~nm}$. Commercially available, film-coated tablets, containing $50 \mathrm{mg}$ sildenafil as sildenafil citrate, were used in this study $[7,8]$.

\section{Results and Discussion}

The method was fully validated according to the ICH (International Conference on Harmonization) guidelines by determination of linearity, precision, accuracy, limit of detection and limit of quantification. Linearity of the method was tested in the range of: 2 - $100 \mathrm{mg} \mathrm{mL}-1$ sildenafil [9]. Experimental data showed high level of linearity which was proved with the value for the correlation coefficient $(\mathrm{R} 2=0.9994)$.

Limit of Detection (LOD) and Quantification (LOQ) of the method were tested in the range of: $20-200 \mathrm{ng} \mu \mathrm{L}-1$ sildenafil. The results were: $0.23 \mathrm{ng}$ and $0.68 \mathrm{ng}$ for LOD and LOQ, respectively (9.2 ng $\mu \mathrm{L}-1$ and $27.2 \mathrm{ng} \mathrm{mL}-1$ for LOD and LOQ, respectively, obtained with $25 \mu \mathrm{L}$ injected) $[10,11]$. Selectivity of the method was proved with the chromatographic peak resolution obtained between sildenafil and tadanafil $(\mathrm{Rs}=10,5)$ (Figures 4-5) and the characteristic UV-spectrum. Mean recovery for sildenafil was between 99,74_\% and 100,88_\% indicating that the developed method was accurate for determination of sildenafil in pharmaceutical formulation [12,13]. The proposed method was successfully applied for determination of sildenafil in film-coated tablets, containing $50 \mathrm{mg}$ sildenafil as sildenafil citrate (Figure 5) [14-16]. The details are further illustrated in the following examples.

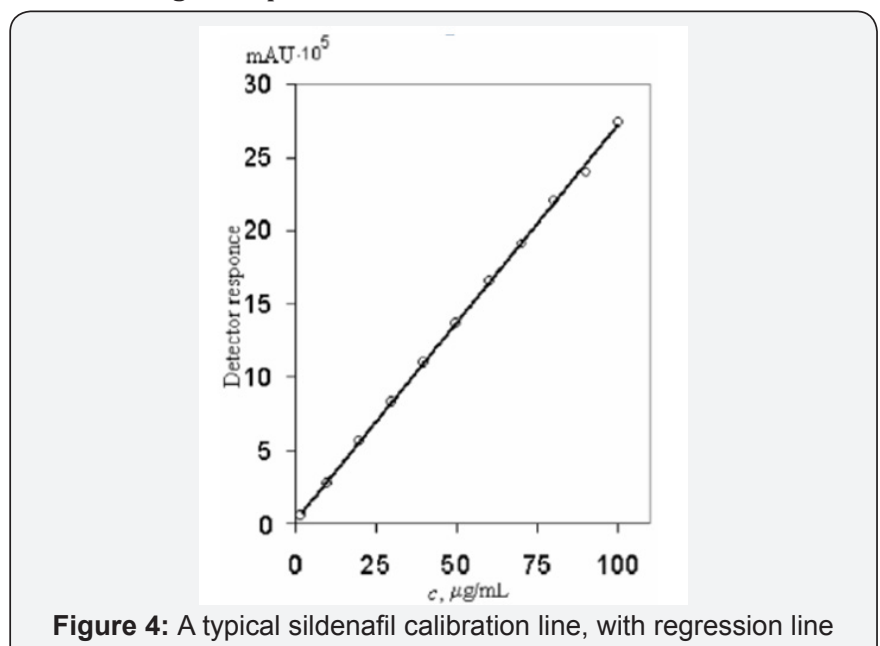

Figure 4: A typical sildenafil calibration line, with regression line Abs $=27066$ conc. +14033 , and R2 $=0.9994$.

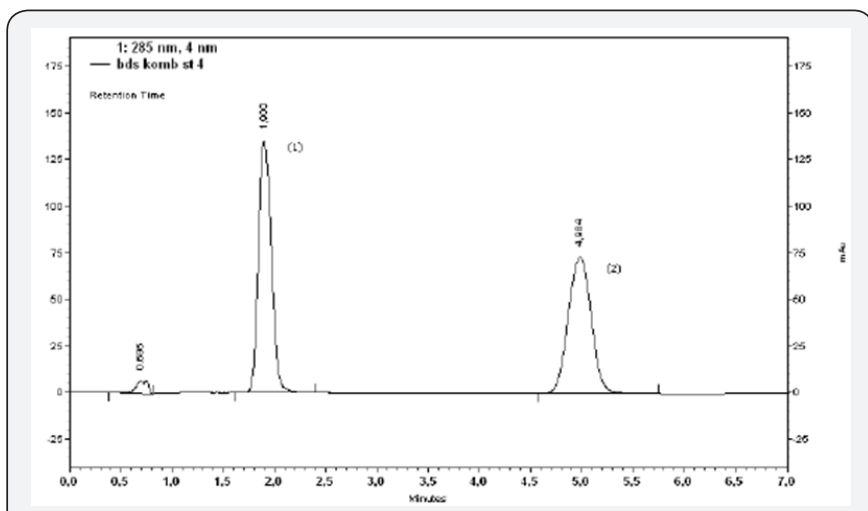

Figure 5: Typical chromatogram obtained from a mixed standard solution: sildenafil (1), tadanafil (2).

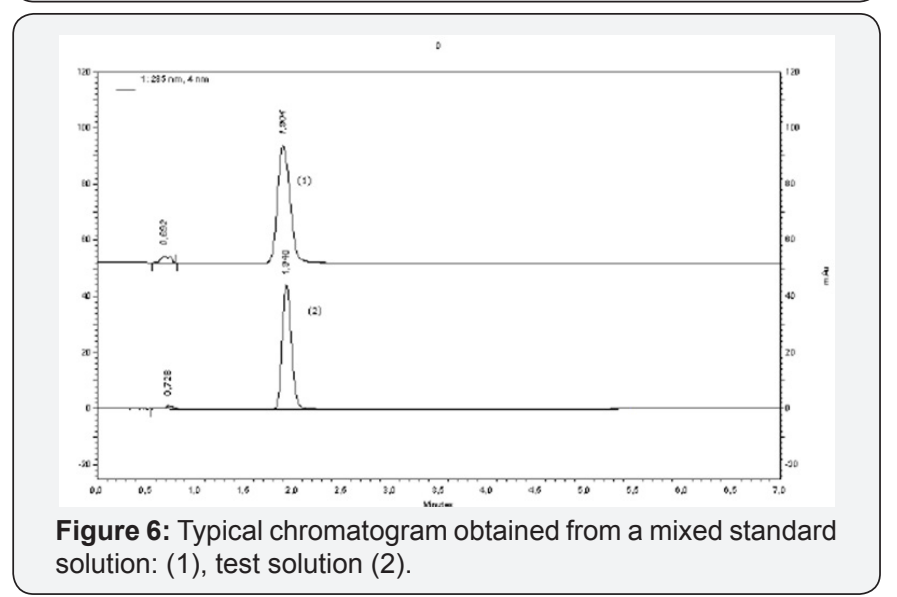

Example 1: General Preparation of Sildenafil Base

In a 10 Litre 3-necked flask, equipped with stirrer, thermometer and reflux condenser, methylenedichloride (6.6Litre) was charged and 4-ethoxy-3-(1-methyl-7-oxo-3- 
propyl-6,7-dihydro-1H-pyrazolo[4,3-d]pyrimidin-5-yl)benzene1-sulfonylchloride (823_gm; $2 \times 10^{3} \mathrm{mmoles}$ ) was added at $25-30 \_{ }^{\circ} \mathrm{C}$. After the dissolution $\mathrm{N}$-methyl piperazine(240_gm; $39 \times 10^{3}$ mmoles)was added at $25-30{ }_{-}^{\circ} \mathrm{C}$ in $15-20$ min. The reaction mixture was stirred properly and diisopropyl ethyl amine (262.5_gm; $2.03 \times 10^{3}$ mmoles) was added, the resultant mixture was maintained at $20_{-}^{\circ} \mathrm{C}$ to $30_{-}^{\circ} \mathrm{C}$ for $2.5 \mathrm{~h}$. Methylene dichloride was distilled under atmospheric pressure $760 \mathrm{~mm} /$ Hg. Charge deionized water (1.64 Litre) in residue and stir to form slurry, which was filtered and product was washed with deionized water ( 0.82 Litre) to give a wet sildenafil base. The wet product was dried under vacuum of about $10 \mathrm{mmHg}$ at 65 _oC for 10 hrs to give sildenafil base 827_gm (HPLC purity-99.5_\% and molar yield of 87_\%).

\section{Example 2:}

In a 10 Litre 3-necked flask equipped with stirrer, thermometer and reflux condenser, methylene dichloride (6.6Litre) was charged and 4-ethoxy-3-(1-methyl-7-oxo-3propyl-6,7-dihydro-1H-pyrazolo[4,3-d]pyrimidin-5-yl)benzene1-sulfonylchloride (823_gm; $2 \times 10^{3} \mathrm{mmoles}$ ) was added at 25 $30 \_{ }^{\circ} \mathrm{C}$. After the dissolution add $\mathrm{N}$-methyl piperazine (240_gm; $2.39 \times 10^{3}$ mmoles) at $25-30{ }_{-}^{\circ} \mathrm{C}$ in $15-20$ mins. The reaction mixture was stirred properly and a mixture of diisopropyl ethyl amine(335_gm; $\left.2.59 \times 10^{3} \mathrm{mmoles}\right)$ and triethyl amine (262.5_ gm; $2.59 \times 10^{3}$ mmoles) was added. The resultant mixture was maintained at ambient temperature for 2.5_h. Methylene dichloride was distilled under atmosphericpressure $760 \mathrm{~mm} /$ Hg. Charge deionized water (1.64 Litre) in residue and stir to form slurry, which was filtered and product was washed with deionized water $(0.82$ Litre) to give a wet Sildenafil base. The wet product was dried under vacuum of $10 \mathrm{mmHg}$ at $65_{-}^{\circ} \mathrm{C}$ for $10 \mathrm{hrs}$ to give sildenafil base 779 _gm (HPLC purity-99.5_\% and molar yield of 82_\%).

\section{Example 3:}

In a 10 Litre 3-necked flask equipped with stirrer, thermometer and reflux condenser, methylene dichloride (6.6Litre) was charged and 4-ethoxy-3-(1-methyl-7-oxo-3propyl-6,7-dihydro-1H-pyrazolo[4,3-d]pyrimidin-5-yl)benzene1-sulfonylchloride (823_gm; $2 \times 10^{3}$ mmoles) was added 25$30 \_{ }^{\circ} \mathrm{C}$. After the dissolution add $\mathrm{N}$-methyl piperazine $\left(240 \_\mathrm{gm}\right.$; $2.39 \times 10^{3}$ mmoles) at $25-30{ }_{-}^{\circ} \mathrm{C}$ in $15-20$ mins. The reaction mixture was stirred properly and a mixture of diisopropyl ethyl amine (52.6_gm; $0.406 \times 10^{3} \mathrm{mmoles}$ ) and triethylamine (164.6_ gm; $\left.1.626 \times 10^{3} \mathrm{mmoles}\right)$ was added.The resultant mixture was maintained at $25_{-}^{\circ} \mathrm{C}$ to $30_{-}^{\circ} \mathrm{C}$ temperature for 2.5 h. Methylene dichloride was distilled under atmospheric pressure $760 \mathrm{~mm} /$ Hg. Charge deionized water (1.64 Litre) in residue and stir to form slurry, which was filtered and product was washed with water ( 0.82 Litre) to give a wet sildenafil base. The wet product was dried under vacuum of $10 \mathrm{mmHg}$ at $65_{-}^{\circ} \mathrm{C}$ for $10 \mathrm{hrs}$ to give sildenafil base 872_gm (HPLC purity-99.8_\% and molar yield of 91.7_\%).

\section{Example 4: Synthesis of Sildenafil Citrate (Form I)}

In a 50-Litre glass assembly, deionised water (21 Litre) was charged and sildenafil base (840_gm; $1.769 \times 10^{3} \mathrm{mmoles}$ ) was added to it at $25-30_{-}^{\circ} \mathrm{C}$. The reaction mixture was heated to 60 $65{ }^{\circ} \mathrm{C}$ for $1 \mathrm{~h}$. Citric acid (370_gm; $1.76 \times 10^{3}$ mmoles) was added to the pre heated reaction mixture. The resultant mixture was further heated up and maintained at $80-85_{-}^{\circ} \mathrm{C}$, for $1 \mathrm{~h}$ and then charcoal treatment given at same temperature. Filter the reaction mass. Filtrate was allowed to cooled to $10-15_{-}^{\circ} \mathrm{C}$, resultant product obtained was filtered and washed with deionised water (0.84 Litre). The product was dried in vacuum (about $10 \mathrm{~mm} \mathrm{Hg}$ ) at 75_oC as a polymorphic form I of sildenafil citrate salt $1.0_{-} \mathrm{kg}$. (HPLC purity-99.9_\% and molar yield of 85_\%).

\section{Example 5: Synthesis of Sildenafil Citrate (Form I)}

In a 500 Litre SS reactor, 4-ethoxy-3-(1-methyl-7-oxo-3propyl-6,7-dihydro-1H-pyrazolo[4,3-d]pyrimidin-5-yl)benzene1-sulfonyl chloride (30_kg) was mixed with methylene dichloride (240 Litre) at $25_{-}^{\circ} \mathrm{C}$ to $30_{-}^{\circ} \mathrm{C}$ temperature, followed by addition of $\mathrm{N}$-methyl piperazine $(8.1 \mathrm{~kg})$ at $25-30{ }_{-}^{\circ} \mathrm{C}$ in $45-60$ mins. After the addition the reaction mixture was stirred properly and a mixture of diisopropyl ethyl amine (2.0_kg) and triethyl amine (6.0_kg) was added, the resultant mixture was maintained at $25_{-}^{\circ} \mathrm{C}$ to $30 \_{ }^{\circ} \mathrm{C}$ temperature for $3-4$ _h. Methylene dichloride was distilled under atmospheric pressure $760 \mathrm{~mm} / \mathrm{Hg}$. Charge deionized water (60 Litre) in residue and stir properly to form slurry, which was filtered and the product was washed with deionised water (30 Litre) to give a wet sildenafil base. The wet product was dried under vacuum of $10 \mathrm{mmHg}$ to give sildenafil base 33.0_ kg (HPLC purity-99.8_\% and molar yield of 95_\%).

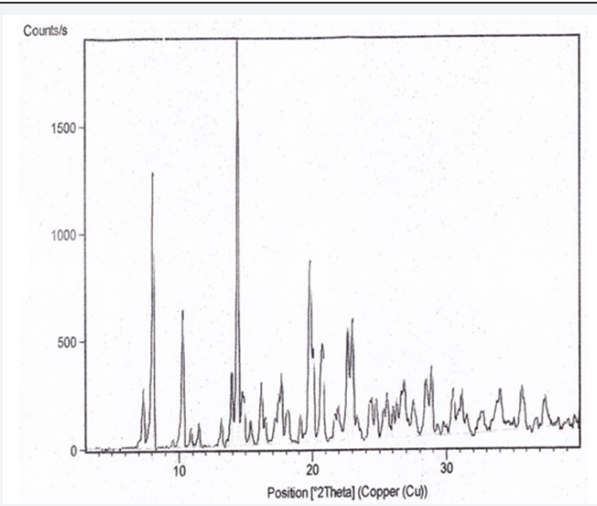

Figure 7: The powder X-Ray diffraction is given in Figure 7.

In a 1200 Litre SS reactor, sildenafil base $(30 \mathrm{~kg})$ was mixed with water $\left(750\right.$ Litre.) at $25-30^{\circ} \mathrm{C}$ and the reaction mixture heated to $60-65_{-}^{\circ} \mathrm{C}$. Citric acid $(13.2 \mathrm{~kg})$ was added to the pre heated reaction mixture and the resultant mixture was further heated to $80-85_{-}^{\circ} \mathrm{C}$ for $1 \mathrm{~h}$. The reaction mixture was treated with carbon charcoal and then filtered. The filtrate obtained was cooled to $10-15^{\circ} \mathrm{C}$, resultant product obtained was filtered and washed with deionised water. The product was dried in vacuum $(10 \mathrm{~mm} \mathrm{Hg})$ at $75_{-}^{\circ} \mathrm{C}$ as a polymorphic form I of sildenafil citrate 
salt 35.5-36_kg. (HPLC purity-99.9_\% and molar yield of 85_\%)

(Table 1) (Figures 7,8).

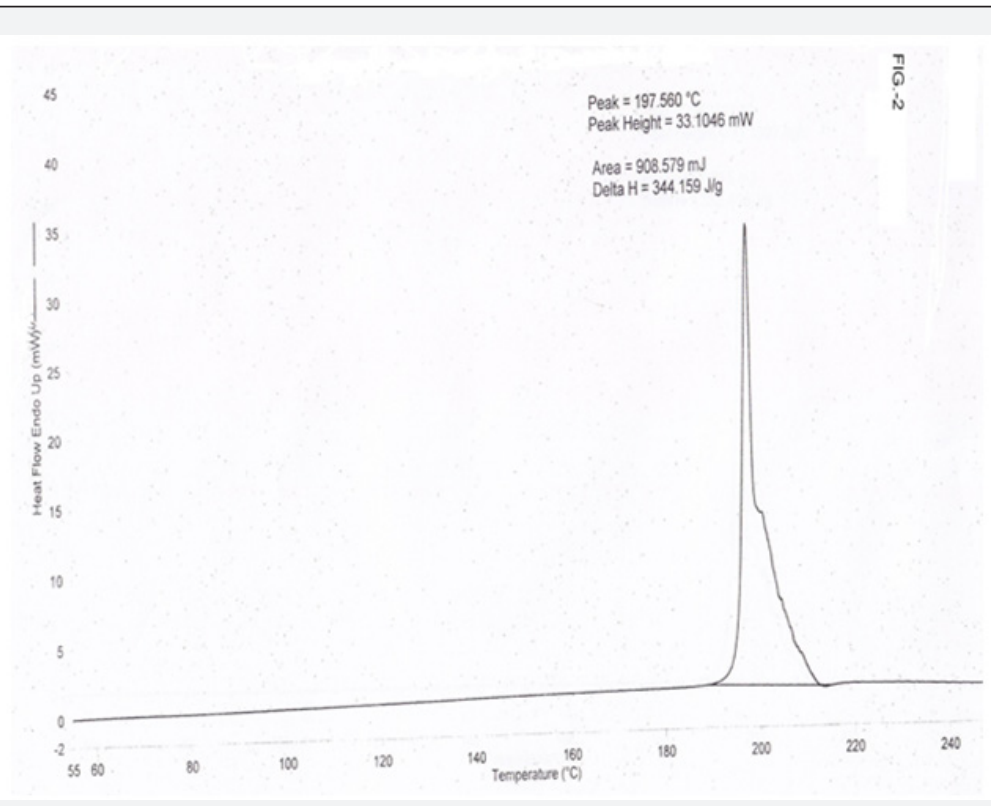

Figure 8.

Table 1: A table for $2 \theta$ values of Sildenafil citrate polymorphic form I.

\begin{tabular}{|c|c|c|c|c|c|c|}
\hline No. & Pos. [02 Th.] & d-spacing & Significance & Rel. Int. [\%] & Height & FWHM [02 Th.] \\
\hline 1 & 7.3764 & 11.94471 & 6.2702 & 20.43 & 268.55 & 0.1968 \\
\hline 2 & 8.1127 & 10.8985 & 8.2537 & 67.21 & 1262.36 & 0.1378 \\
\hline 3 & 9.5727 & 9.27806 & 1.0402 & 1.65 & 36.90 & 0.1181 \\
\hline 4 & 10.3293 & 8.56425 & 7.2082 & 35.73 & 587.30 & 0.1574 \\
\hline 5 & 10.9047 & 8.11361 & 1.1678 & 3.71 & 81.21 & 0.1181 \\
\hline 6 & 11.4934 & 7.69927 & 1.6423 & 4.93 & 108.04 & 0.1181 \\
\hline 7 & 13.1887 & 6.71317 & 2.474 & 6.71 & 125.94 & 0.1378 \\
\hline 8 & 13.9689 & 6.33994 & 2.7846 & 18.33 & 344.26 & 0.1378 \\
\hline 9 & 14.4271 & 6.13961 & 9.0055 & 100 & 1878.24 & 0.1378 \\
\hline 10 & 14.9079 & 5.94267 & 0.8893 & 7.38 & 194.15 & 0.0984 \\
\hline 11 & 15.3464 & 5.77383 & 1.0773 & 4.82 & 105.62 & 0.1181 \\
\hline 12 & 16.1917 & 5.47426 & 1.5703 & 12.65 & 277.21 & 0.1181 \\
\hline 13 & 16.483 & 5.37816 & 1.4703 & 5.98 & 112.35 & 0.1378 \\
\hline 14 & 17.1452 & 5.17192 & 1.4148 & 7.74 & 113.04 & 0.1771 \\
\hline 15 & 17.4416 & 5.08469 & 0.845 & 10.21 & 223.67 & 0.1181 \\
\hline 16 & 17.6803 & 5.01656 & 2.0602 & 14.99 & 328.43 & 0.1181 \\
\hline 17 & 18.0743 & 4.90808 & 0.8691 & 9.4 & 154.41 & 0.1574 \\
\hline 18 & 19.1325 & 4.63896 & 4.4349 & 10.38 & 124.04 & 0.2165 \\
\hline 19 & 19.8725 & 4.46784 & 10.8052 & 81.97 & 829.02 & 0.2558 \\
\hline 20 & 20.123 & 4.41278 & 2.7797 & 20.47 & 384.52 & 0.1378 \\
\hline 21 & 20.2422 & 4.26212 & 3.8423 & 25.86 & 377.8 & 0.1771 \\
\hline 22 & 21.664 & 4.10225 & 1.3778 & 6.84 & 112.38 & 0.1574 \\
\hline 23 & 21.934 & 4.05234 & 0.8637 & 7.22 & 158.1 & 0.1181 \\
\hline 24 & 22.6644 & 3.92339 & 2.6455 & 28.17 & 529.09 & 0.1378 \\
\hline
\end{tabular}




\section{Organic and Medicinal Chemistry International Journal}

\begin{tabular}{|c|c|c|c|c|c|c|}
\hline 25 & 23.0446 & 3.85952 & 4.2792 & 32.63 & 536.27 & 0.1574 \\
\hline 26 & 23.3581 & 3.80843 & 0.8911 & 6.1 & 114.54 & 0.1378 \\
\hline 27 & 24.2522 & 3.67001 & 1.048 & 10.05 & 165.16 & 0.1574 \\
\hline 28 & 24.7131 & 3.6026 & 1.7664 & 11.03 & 181.25 & 0.1574 \\
\hline 29 & 25.2918 & 3.52147 & 0.8595 & 6.37 & 139.48 & 0.1181 \\
\hline 30 & 25.5938 & 3.4806 & 3.209 & 14.95 & 196.52 & 0.1968 \\
\hline 31 & 25.998 & 3.42739 & 1.2909 & 7.27 & 136.6 & 0.1378 \\
\hline 32 & 26.2996 & 3.38876 & 1.3517 & 7.83 & 171.58 & 0.1181 \\
\hline 33 & 26.8428 & 3.32142 & 1.1524 & 13.69 & 257.13 & 0.1378 \\
\hline 34 & 27.5147 & 3.24181 & 2.7231 & 17.37 & 163.15 & 0.2755 \\
\hline
\end{tabular}

\section{Conclusion}

The present process, which describes the manufacturing process of sildenafil citrate, which e is a selective inhibitor of Cyclicguanosine Monophosphate (cGMP) specific Phosphodiesterase Type 5 (PDE 5), has the advantage of scaling up to the industrial level of production. The results of the validation demonstrated that the proposed analytical procedure is accurate, precise and reproducible for sildenafil analysis in pharmaceutical dosage forms. Furthermore, this procedure is relatively inexpensive and simple and is particularly suitable for routine analyses when tandem mass spectrometric detection is not available.

Additionally, it is important to mention that decreased consumption of organic solvent considerably reduces the laboratory expenses. The process uses safe reagents in the process which makes it better for industrial scale operations. The yields in the process are high which makes it a cost effective process. Residual solvents play a very important role in the impurity profile of APIs as per the ICH Guidelines ICH Q3C_(R4). In this process by carrying out the final step of condensation of Sildenafil base and citric acid in the aqueous medium followed by water crystallization.

\section{References}

1. Breslow R (1996) The Greening of Chemistry. Chem \& Eng News pp. 72.

2. E Ernst (2002) Adulteration of Chinese herbal medicines with synthetic drugs, a systematic review. J Intern Med 252(2): 107-113.

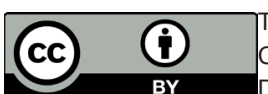

his work is licensed under Creative

Commons Attribution 4.0 License

OOI: 10.19080/OMCIJ.2018.05.555674
3. Anastas PT, Williamson TC (1998) Green Chemistry: Frontiers in Benign Chemical Syntheses and Processes. Oxford University Press: Oxford, UK, Europe.

4. Anastas P, Warner J (1998) Green Chemistry: Theory and Practice. Oxford University Press: Oxford, UK, Europe.

5. Sheldon RA (1992) Organic synthesis; past, present and future. Chem Ind 23: 903-906.

6. Sheldon RA (1994) Consider the environmental quotient. Chem Tech 24: 38-47.

7. Jimenez-Gonzalez C, Curzons AD, Constable DJC, Cunningham VL (2004) Int J LCA 9: 114-121.

8. Curzons AD, Jimenez-Gonzalez C, Duncan AL, Constable DJC, Cunningham VL (2007) Int J LCA 12: 272-280.

9. Sheldon RA (2005) Green solvents for sustainable organic synthesis: state of the art. Green Chem 7(5): 267-278.

10. FDA Consumer Health Information (2009) Hidden Risks of Erectile Dysfunction Treatments Sold Online.

11. Jer-Huei Lin (2006) Identification of a Sildenafil Analogue Adulterated in Two Herbal Food Supplements. Journal of Food and Drug Analysis 14(3): 260-264.

12. Hakan Goker (2012) Chromatographic Separation and Identification of Sildenafil and Yohimbine Analogues Illegally Added in Herbal Supplements. Biochemistry, Genetics and Molecular Biology.

13. (2012) Four Fake Doctors Jailed. The Daily Star.

14. (2012) Indian herbal 'Sandhi Sudha' floods Bangladesh markets.

15. (2013) Indications and Clinical Use, Product Monograph of VIAGRA (sildenafil citrate).

16. PATENTS- EP 1002798, EP 1779852, EP 0916675, US6066735 US6204383, US2010048897, W00119827, W0122918, and W02004072079.

Your next submission with Juniper Publishers
will reach you the below assets
- Quality Editorial service
- Swift Peer Review
- Reprints availability
- E-prints Service
- Manuscript Podcast for convenient understanding
- Global attainment for your research
- Manuscript accessibility in different formats
( Pdf, E-pub, Full Text, Audio)
- Unceasing customer service
Track the below URL for one-step submission
https://juniperpublishers.com/online-submission.php

